\title{
LA GARANTÍA O DERECHO DE INDEMNIDAD LABORAL Y SU RELACIÓN CON LA PRUEBA INDICIARIA
}

\author{
José FranCisco CASTRO CASTRO* \\ Universidad Pedro de Valdivia
}

\begin{abstract}
RESUMEN: La presente investigación aborda desde una perspectiva teórica y práctica la institución jurídica conocida como garantía o derecho de indemnidad laboral, la cual está destinada a proteger al trabajador frente a las represalias del empleador, para lo cual se exponen el origen, sus fundamentos y los elementos que la conforman. En el plano conceptual, se recogen las principales definiciones existentes y el autor propone una definición propia para nuestro sistema normativo, a partir de la opción de considerar que se trata de un derecho de indemnidad y no precisamente de una garantía. Un profundo y especial tratamiento se le da en este trabajo a la relación existente entre el derecho de indemnidad y la prueba indiciaria, particularmente a partir de lo que han sido las sentencias de los tribunales de justicia nacionales.
\end{abstract}

Palabras clave: Derecho de indemnidad, garantía de indemnidad, represalia, prueba indiciaria.

ABSTRACT: The present investigation approaches from a theoretical and practical perspective the well-known legal institution like guarantee or right of labor indemnity, which is destined to protect to the worker as opposed to the retaliation of the employer, for which the origin, its foundations and the elements are exposed that conform it. In the conceptual plane, the main existing definitions take shelter and the author proposes an own definition for our normative system, from the option to consider that she is an indemnity right and not indeed about a guarantee. A deep and special treatment occurs in this work to the existing relation between the right of indemnity and the circumstantial evidence him, particularly from which they have been the sentences of the national courts of justice.

Key words: Right of indemnity, guarantee of indemnity, retaliation, circumstantial evidence.

\section{INTRODUCCIÓN}

El ejercicio de todo derecho está íntimamente ligado a los mecanismos de que se dispone para hacerlo efectivo y a la ausencia de consecuencias negativas para aquel que lo ejerce. En cuanto al Derecho del Trabajo este punto cobra más relevancia todavía, dada la relación de dependencia o subordinación que caracteriza al vínculo laboral. En efecto, la desigualdad de poder y económica entre empleador y trabajador, constituye un escenario propicio para la existencia de limitaciones o trabas para el ejercicio de derechos por parte del trabajador. Por ello, la garantía o derecho de indemnidad laboral juega en esta materia un papel central, ya que es la principal herramienta de que dispone el trabajador para hacer frente a las represalias del empleador $y$, de esta forma, poder ejercer libremente sus derechos.

La garantía o derecho de indemnidad constituye en Chile una institución jurídica relativamente nueva, ya que recién comenzó a aplicarse a partir del año 2008 junto con el naciente procedimiento de tutela laboral. A lo largo de los años posteriores, esta institución ha ido mostrando progresivamente su relevancia para combatir las represalias ejercidas por

\footnotetext{
Abogado de la Universidad de Chile. Magíster en Derecho de la Empresa de la Pontificia Universidad Católica de Chile. Profesor de Derecho Laboral de la Universidad Pedro de Valdivia. Alumno del Programa de Doctorado en Derecho de la Pontificia Universidad Católica de Valparaíso y Beneficiario Beca Postgrado PUCV.
} 
los empleadores en contra de sus trabajadores, gatilladas por el ejercicio de alguna acción judicial o por las labores fiscalizadoras realizadas por la Dirección del Trabajo.

Este trabajo se ha planteado con el objetivo de hacer una exposición sobre el origen y desarrollo que ha tenido la garantía o derecho de indemnidad en Chile, así como sobre su íntima vinculación con otra institución relativamente reciente, cual es la prueba indiciaria. Para ello, hemos dividido el trabajo en tres partes. La primera está destinada a abordar el origen y fundamento de la garantía o derecho de indemnidad, así como sus aspectos conceptuales. Además, en esta parte del trabajo se analiza en profundidad un tema no abordado hasta ahora por la doctrina ni por la jurisprudencia nacional, cual es si efectivamente la garantía de indemnidad constituye una garantía o, más bien, estamos frente a un derecho de indemnidad.

Los elementos que conforman esta garantía o derecho de indemnidad son descritos y analizados en la segunda parte de esta investigación, con la referencia específica a nuestra realidad nacional y a cómo nuestros tribunales han ido interpretando estos elementos y los han ido aplicando en sus fallos.

La tercera parte del trabajo, en tanto, está abocada en su totalidad a la relación que existe entre la garantía o derecho de indemnidad y la técnica probatoria conocida como "prueba indiciaria", contemplada en el artículo 493 del Código del Trabajo. Esta parte del trabajo está desarrollada en dos puntos, en el primero se explica la centralidad o especial relevancia que tiene la prueba indiciaria en materia de garantía o derecho de indemnidad. En segundo lugar, exponemos algunas tendencias manifestadas a través de sus fallos por los Tribunales del Trabajo y por algunas Cortes de Apelaciones en relación con esta materia.

El presente trabajo finaliza con las conclusiones personales del autor y con la bibliografía consultada.

\section{ORIGEN Y ASPECTOS CONCEPTUALES}

\subsection{ORIGEN Y FUNDAMENTO DE LA GARANTÍA DE INDEMNIDAD}

La Ley 20.087, de 3 de enero de 2006, que estableció un nuevo procedimiento para la sustanciación de los juicios del trabajo, incorporó en el Libro V del Código del Trabajo, un párrafo específicamente dedicado a regular un procedimiento especial denominado "Procedimiento de Tutela Laboral", el que tiene por finalidad resolver las cuestiones suscitadas en la relación de trabajo que afecten los derechos fundamentales de los trabajadores, entendiéndose por estos los enumerados en el artículo 485 del Código del Trabajo. Este procedimiento, como toda la nueva justicia laboral, comenzó a implementarse de manera gradual en el país, a partir del 31 de marzo de 2008.

Dentro de las innovaciones introducidas por el procedimiento de tutela laboral, se contempla la posibilidad de que este se aplique para resolver las denuncias hechas por trabajadores respecto de las represalias ejercidas en su contra por el empleador, en razón o como consecuencia de la labor fiscalizadora de la Dirección del Trabajo o por el ejercicio de acciones judiciales (artículo 485 inciso tercero del Código del Trabajo), lo que en doctrina, jurisprudencia y derecho comparado se conoce mayoritariamente como "garantía de indemnidad". 
Esta novedad fue introducida en el inciso tercero del artículo 485, el cual en primer término dispone que los derechos y garantías a que se refieren los incisos anteriores, se entenderá que resultan lesionados cuando el ejercicio de las facultades que la ley le reconoce al empleador limitan el pleno ejercicio de aquellos sin justificación suficiente, en forma arbitraria o desproporcionada, o sin respeto a su contenido esencial. Luego, y es lo que para efectos de este trabajo nos interesa, este mismo inciso establece la garantía de indemnidad al disponer textualmente: "En igual sentido se entenderán las represalias ejercidas en contra de trabajadores, en razón o como consecuencia de la labor fiscalizadora de la Dirección del Trabajo o por el ejercicio de acciones judiciales".

Cabe señalar que el procedimiento de tutela laboral fue incluido inicialmente en el mensaje del Ejecutivo con el nombre de "Procedimiento de Tutela de Derechos Fundamentales", pues se estimó "de vital importancia, siguiendo muy de cerca las experiencias comparadas, diseñar un modelo concreto de tutela de los derechos fundamentales al interior de la empresa a través de un procedimiento especial que dé cuenta de una serie de garantías procesales conducentes a una adecuada y eficaz protección"1.

La garantía de indemnidad, por su parte, no estaba contenida en el texto del mensaje que el Ejecutivo envió inicialmente al Congreso Nacional, sino que ella fue incorporada recién en segundo trámite constitucional en el Senado, a través de una indicación del senador Edgardo Boeninger, la que fue aprobada con algunas modificaciones primero en la Comisión de Trabajo y Seguridad Social del Senado y luego en la Sala del Senado, pasando a ser parte del texto final de lo que llegaría a ser la Ley 20.087.

El origen y el fundamento de la garantía de indemnidad están vinculados indudablemente a la necesidad para quien busca hacer efectivo un derecho, de tener protección jurisdiccional o administrativa al ejercerlo, de forma tal que dicho ejercicio no conlleve alguna consecuencia negativa para su titular. El Derecho del Trabajo ha pretendido desde su origen proteger al trabajador asalariado de los riesgos de la subordinación, tutelando su posición de "contratante débil" y buscando compensar, en cierta medida, la desigualdad entre las partes que caracteriza al contrato de trabajo ${ }^{2}$. Por ello, se ha afirmado que "el objetivo de protección de los intereses personales del trabajador ha sido durante la etapa inicial de este sector del ordenamiento la finalidad más característica del Derecho del Trabajo"3.

Una de las críticas más comunes que se le hacen en este sentido al Derecho del Trabajo radica precisamente en su poca eficacia, "debida, en buena medida, a la falta de exigencia de los derechos que legalmente les asisten por parte de los trabajadores, amenazados por el temor a la pérdida del puesto de trabajo o a algún otro perjuicio en sus intereses profesionales" ${ }^{4}$. Por ello, es evidente que el conjunto de instrumentos tuitivos del trabajo subordinado o dependiente que establece el Derecho Laboral requiere, para ser verdadera-

\footnotetext{
$1 \quad$ Mensaje No 4-350, de 22-09-2003, de S.E. el Presidente de la República, con el que inicia un proyecto de ley que sustituye el Procedimiento Laboral contemplado en el Libro V del Código del Trabajo, p. 7.

2 Álvarez Alonso, Diego. La garantía de indemnidad del trabajador frente a represalias empresariales. Albacete, España: Bomarzo, 2005, p. 14.

3 Martín Valverde, Antonio; Rodríguez-Sañudo Gutiérrez, Fermín; García Murcia, Joaquín. Derecho del Trabajo. Madrid, España: Tecnos, 2007, p. 61.

4 Álvarez Alonso, Diego, op. cit. (n. 2), p. 15.
} 
mente eficaz, la prohibición y sanción de las conductas del empleador de represalia ante el ejercicio de sus derechos por parte del trabajador. Pues bien, hasta antes de esta innovación introducida por la Ley 20.087 conocida como "garantía de indemnidad", los mecanismos de protección de nuestro Derecho ante tales represalias del empleador eran bastante difusos e incompletos.

Como se puede observar, la garantía de indemnidad tiene una importancia central en cualquier sistema jurídico laboral, ya que "el reconocimiento de un derecho debe entrañar no solo la posibilidad de ejercitarlo, sino también la tutela de quien lo ejercita frente a


legal de la garantía de indemnidad se buscó asegurar una real eficacia en la protección de los derechos laborales, impidiendo que el trabajador renuncie a estos por las posibles represalias que pudiera sufrir por parte del empleador.

En España, país cuya institucionalidad laboral constituyó un referente importante en la génesis de lo que sería la Ley 20.087, especialmente en el trabajo previo al proyecto de ley realizado por el Foro para la Reforma a la Justicia Laboral ${ }^{6}$, toda la edificación teórica de la garantía de indemnidad ha sido hecha a partir de la jurisprudencia del Tribunal Constitucional español. Se trata, entonces, de un instituto jurídico de creación jurisprudencial, cuyas primeras sentencias, algo titubeantes, se remontan al año 1993. Esta jurisprudencia ha encontrado su fundamento en el derecho constitucional a la tutela judicial efectiva contemplado en el artículo 24.1 de la Constitución española. En efecto, la construcción del Tribunal Constitucional español está ligada al ejercicio del derecho a la tutela judicial efectiva, ya que la represalia por el ejercicio de ese derecho constituiría, de suyo, una violación del derecho fundamental mismo. Así, la garantía de indemnidad sería "un derecho adjetivo, ligado de forma indisoluble al derecho a la tutela judicial efectiva" trumento básico de libre acceso a los jueces y a los tribunales en defensa de derechos e intereses legítimos.

En cuanto a las normas del Derecho Internacional del Trabajo, es importante destacar en relación con la garantía de indemnidad al Convenio No 158 de la Organización Internacional del Trabajo (OIT), de 1982, no ratificado por Chile, sobre "Terminación de la relación de trabajo por iniciativa del empleador" que, en su artículo 5 letra c), excluye de las causas justificadas para la terminación de la relación de trabajo, el haber presentado el trabajador una queja o haber participado en un procedimiento entablado contra un empleador por supuestas violaciones de leyes o reglamentos, o haber recurrido ante las autoridades administrativas competentes.

6 El Foro para la Reforma a la Justicia Laboral fue una instancia conformada por académicos, jueces, abogados litigantes y representantes de las instituciones públicas relacionadas, coordinada por el profesor Patricio Novoa Fuenzalida, cuya finalidad consistió en elaborar un diagnóstico de la situación en que se encontraba la justicia del trabajo y previsional, así como realizar propuestas de reforma, tanto en lo orgánico como procedimental, en lo que refiere a los juicios laborales y previsionales. Las propuestas de este Foro constituyeron parte importante de los proyectos de ley que culminaron su tramitación parlamentaria con la aprobación de las leyes $\mathrm{n}^{\text {os }} 20.022,20.023$ y 20.087, referidas a lo orgánico, al procedimiento de ejecución y al procedimiento en juicio del trabajo, respectivamente.

7 Igartua Miró, María Teresa. La Garantía de Indemnidad en la Doctrina Social del Tribunal Constitucional. Madrid, España: Consejo Económico Social, 2008, p. 36.
} 
De esta forma, sobre la garantía de indemnidad, el planteamiento del Convenio 158 de la OIT es todavía más amplio que el del sistema jurídico español, ya que en dicho instrumento internacional se consideran también incluidas las reclamaciones ante las autoridades administrativas (como la Inspección del Trabajo, por ejemplo) e incluso eventualmente las quejas que se esgrimen ante el propio empleador.

También en este punto cabe mencionar la Recomendación No 119 de la OIT, de 1963, sobre "Terminación de la Relación de Trabajo por iniciativa del empleador", cuyo artículo $3^{\circ}$ está redactado en términos casi idénticos a lo expuesto sobre el Convenio No 158 .

Como podemos ver, nada se dice en los instrumentos emanados de la OIT sobre otras medidas del empleador distintas del despido, las que pudieran igualmente obedecer a una motivación de represalia frente al trabajador que reclama por sus derechos.

En el caso de nuestro país, la redacción del inciso tercero del artículo 485 del Código del Trabajo es bastante amplia, ya que comprende las represalias ejercidas en contra de trabajadores, ya sea en razón o como consecuencia de la labor fiscalizadora de la Dirección del Trabajo, o por el ejercicio de acciones judiciales. Sobre este aspecto profundizaremos más adelante en el desarrollo del presente trabajo.

\subsection{CONCEPTO DE GARANTÍA DE INDEMNIDAD}

La Real Academia Española de la Lengua define indemnidad como "estado o situa-


tido que debe dársele desde el punto de vista jurídico-laboral, ya que la garantía de indemnidad está vinculada esencialmente a la ausencia o exención de sanciones o represalias para quien ejerce un derecho o hacer valer sus posiciones jurídicas.

En derecho comparado se suele hacer la distinción entre garantía de indemnidad en sentido lato o "indemnidad genérica” y garantía de indemnidad en sentido estricto. La garantía de indemnidad en sentido lato o "indemnidad genérica" consiste en una noción amplia referida al derecho adjetivo que acompaña a todos y cada uno de los derechos fundamentales, vedando toda reacción represiva de su ejercicio, ya que a todos ellos los acompaña la prohibición de cualquier perjuicio o menoscabo que se infiera como consecuencia de su lícito ejercicio. Podrían agregarse a este concepto amplio de indemnidad, ciertas regulaciones de la legislación laboral que también protegen al trabajador de daños o perjuicios asociados al ejercicio de determinados derechos laborales ${ }^{9}$. Por ejemplo, se podrían incluir dentro de esta definición las garantías establecidas en torno a los trabajadores que tienen algún tipo de representación sindical, las referidas a las normas de protección de la maternidad, las normas relativas a la protección de la salud y seguridad de los trabajadores, etc.

Por su parte, la garantía de indemnidad en sentido estricto estaría vinculada al derecho a la tutela judicial efectiva, referido al derecho al libre acceso a la jurisdicción, aunque con cierta autonomía, protegiendo a la persona que ejercita acciones judiciales frente a todo tipo de represalias que ello pudiera acarrear y que, en el específico ámbito de las relaciones

www.rae.es, sitio consultado el 20 de enero de 2012.

9 Álvarez Alonso, Diego, op. cit. (n. 2), p. 38. 
laborales, implica que el poder de dirección no puede utilizarse para perjudicar al trabajador como consecuencia del planteamiento de algún litigio contra su empleador.

En el desarrollo del presente trabajo, cuando hablamos de garantía de indemnidad, nos referimos a la garantía de indemnidad en sentido estricto, por ser el concepto más preciso para abordar la problemática de las represalias en el mundo del trabajo, con la particularidad de que en Chile esta institución está diseñada también para dar cobertura a las represalias ejercidas por el empleador en contra del trabajador en razón o como consecuencia de la intervención administrativa del órgano fiscalizador (la Dirección del Trabajo). La garantía de indemnidad en sentido lato o "indemnidad genérica" es más bien una construcción doctrinaria que no tiene aplicación práctica por sí misma como concepto dentro de nuestro sistema jurídico-laboral.

Pues bien, siguiendo con la garantía de indemnidad en sentido estricto, la doctrina española ha entregado distintas definiciones, precisamente a partir de las sentencias del Tribunal Constitucional español. Así, se le ha definido como "la prohibición de cualquier género de represalia empresarial contra el trabajador, que traiga su causa de forma directa en el ejercicio por parte de este de su legítimo derecho a la tutela judicial efectiva, incluyendo determinados actos previos al propio proceso" ${ }^{10}$. También se ha dicho que la garantía de indemnidad puede definirse esencialmente:

"Como una peculiar vertiente del derecho a la tutela judicial efectiva que ofrece su cobertura a quien ejercita su derecho de acudir al proceso frente a cualquier injerencia represiva pública o privada, incluidas las represalias que la empresa pudiera adoptar contra un trabajador como consecuencia del planteamiento por este de una acción judicial contra aquella"11.

En cuanto a la doctrina nacional, el profesor José Luis Ugarte ha identificado la garantía de indemnidad como "el derecho a no ser objeto de represalias en el ámbito laboral por el ejercicio de acciones administrativas o judiciales" 12 .

La jurisprudencia nacional de los tribunales del trabajo la ha definido, en uno de sus fallos, como "el derecho de toda persona del ejercicio legítimo de sus derechos, y que consiste en no ser objeto de represalias en el ámbito laboral por el ejercicio de acciones administrativas o judiciales" 13 .

A diferencia de lo que ocurre en España, en nuestro país la garantía de indemnidad no está asociada directamente al derecho constitucional a la tutela judicial efectiva, sino que se trata de una norma legal expresa y autónoma incorporada en el Código del Trabajo. Por otro lado, en nuestro sistema jurídico laboral la cobertura es más amplia, ya que además, como se adelantó, se contempla explícitamente la prohibición de ser objeto de represalias

\footnotetext{
10 IgARTUA Miró, María Teresa, op. cit. (n. 7), p. 71.

1 Álvarez Alonso, Diego, op. cit. (n. 2), p. 28.

12 Ugarte Cataldo, José Luis. Tutela de derechos fundamentales del trabajador. Santiago, Chile: LegalPublishing, 2009, p. 36.

13 Sentencia del JLT de Concepción, de fecha 1 de octubre de 2009, en causa RIT T 16-2009.
} 
por la intervención de la autoridad administrativa (Dirección del Trabajo), en cuanto a su función fiscalizadora.

\section{3. ¿GARANTÍA O DERECHO DE INDEMNIDAD?}

A la luz del desarrollo que está teniendo esta institución en nuestro sistema jurídico laboral, surge la interrogante de si estamos frente a una garantía o ante un derecho de indemnidad, especialmente considerando las particularidades de nuestra legislación en la materia. Este ha sido un punto que ha sido obviado en general, tanto por nuestra doctrina como por nuestra jurisprudencia, a partir de la entrada en vigencia de la normativa de la Ley 20.087.

Los autores nacionales ${ }^{14}$, por una parte, se apresuraron en trasladar la fundamentación teórica y el léxico utilizado en España para la garantía de indemnidad a la nueva reglamentación nacional, sin realizar las necesarias distinciones entre un sistema y otro. En efecto, en España claramente se habla de "garantía de indemnidad", ya que se trata, como se ha dicho, de una creación jurisprudencial del Tribunal Constitucional español, que tiene su fundamento en el derecho constitucional a la tutela judicial efectiva, contemplado en el artículo 24.1 de la Constitución española. No existe en dicho país una norma legal de carácter general que establezca la garantía de indemnidad, sino que el tratamiento de esta a nivel legislativo es más bien fragmentario ${ }^{15}$.

En Chile nuestra Constitución no contempla expresamente el derecho a la tutela judicial efectiva, sino que solo se establece en el artículo 19 no 3 la igual protección de la ley en el ejercicio de los derechos, el derecho a defensa jurídica y el debido proceso. Sin embargo, a partir de la sentencia rol No 815, de 19 de agosto de 2008, el Tribunal Constitucional fijó una nueva doctrina que sostiene que, más allá de las normas citadas, la Constitución reconocería el conjunto valórico normativo que configura la tutela judicial efectiva de los derechos e intereses de las personas. Esta doctrina ha sido mantenida hasta la fecha por el citado Tribunal. Para comprender mejor el fundamento de esta doctrina, resulta pertinente transcribir parte del considerando décimo del mencionado fallo:

"Que nuestra Constitución consagra, sin denominarlo así, el invocado derecho a la tutela judicial efectiva, en el inciso primero del artículo 19 , numeral $3^{\circ}$, y en las normas que lo complementan, al reconocerse con fuerza normativa, que todas las personas son iguales en el ejercicio de los derechos, lo que comprende, en nuestro medio, su igualdad de posibilidades ante los órganos jurisdiccionales, incluyendo, en primer término, el derecho a la acción, sin el cual quedaría amenazado e incompleto.

\footnotetext{
14 Entre ellos, Ugarte CaTAldo, José Luis, Tutela de derechos... (n. 12), pp. 36 y 37, y Guidi Moggia, Caterina. "Consagración legal de la garantía de indemnidad en nuestro ordenamiento jurídico laboral”, en: Revista Estudios Laborales, n 2 , Santiago, Chile, 2008, pp. 23-45.

15 En efecto, existen en España normas legales específicas que consagran algunas modalidades de Garantía de Indemnidad como es el caso, por ejemplo, del artículo 17.1 del Estatuto de los Trabajadores, que al efecto dispone: "Serán igualmente nulas las órdenes de discriminar y las decisiones del empresario que supongan un trato desfavorable de los trabajadores como reacción ante una reclamación efectuada en la empresa o ante una acción administrativa o judicial destinada a exigir el cumplimiento del principio de igualdad de trato y no discriminación”.
} 
En efecto, el primer inciso del numeral $3^{\circ}$ del artículo 19 lo reconoce en forma expresa, correspondiendo su titularidad a la persona como sujeto legitimado para su ejercicio, el que está contemplado en una norma autosuficiente y autoejecutiva.

Como complemento necesario, los incisos siguientes establecen garantías normativas del mismo, consistentes en la legalidad del tribunal y del proceso, además del parámetro de densidad material mínima de dichas normas legales, consistentes en las garantías del racional y justo procedimiento, a lo cual se le sumó la investigación, fijan el límite a la autonomía del legislador, a la hora de establecer el marco regulatorio del proceso jurisdiccional, como forma de solución del conflicto y de los actos necesarios para abrirlo, sustanciarlo y cerrarlo"16.

No obstante lo expuesto, no queda claro que en Chile el fundamento de la garantía o derecho de indemnidad esté referido precisamente al derecho a la tutela judicial efectiva, ya que se trata de una institución que tiene vida propia a partir de su consagración en un texto legal expreso, esto es, la norma del artículo 485 inciso tercero del Código del Trabajo. Por otro lado, en la práctica, el ejercicio de esta garantía o derecho de indemnidad en Chile está vinculado más a combatir las represalias del empleador frente a la labor fiscalizadora de la Dirección del Trabajo, que a las que se provocan por el ejercicio de acciones judiciales por parte del trabajador. Por ello, es una institución con particularidades propias, la cual no consiste en un simple traslado del desarrollo doctrinario y jurisprudencial que ella ha tenido en España, sino que corresponde analizar de acuerdo con su contenido material propio y específico. Ello lleva a que efectivamente podamos revisar si se trata de una garantía o más bien consiste en un derecho.

Cabe señalar además que en los propios fallos de los tribunales nacionales no existe uniformidad para referirse a la indemnidad del trabajador como garantía o como derecho. Efectivamente, la mayoría de las sentencias laborales habla de la "Garantía de Indemnidad", pero existen otras que se refieren a la institución como "Derecho de Indemnidad"17, algunas utilizan indistintamente las dos expresiones (garantía y derecho) ${ }^{18} \mathrm{y}$, finalmente, hay otras que omiten adoptar alguna de estas denominaciones y simplemente hacen referencia a la norma establecida en el artículo 485 inciso tercero del Código del Trabajo o directamente se limitan a señalar que "el despido del actor se debió a una represalia por parte de la empresa demandada derivada de las fiscalizaciones de que fue objeto por la Inspección del Trabajo"19.

Entonces, ¿estamos hablando de una garantía o de un derecho de indemnidad? Respecto de este tema, ante todo, es necesario traer a colación la precisión que realiza el profe-

\footnotetext{
16 Sentencia rol No 815, de fecha 19 de agosto de 2008, del Tribunal Constitucional

17 Podemos citar en esta línea, a modo de ejemplo, las sentencias de las causas rol 31-2010 de la Iltma. Corte de Apelaciones de Valdivia, de 29 de abril de 2010; RIT T 3-2010 del JLT de Puerto Montt, de 14 de abril de 2010; RIT T 3-2010 del JLT de Talca, de 21 de abril de 2010; RIT T 5-2008 del JLT de Copiapó, de 23 de febrero de 2009; RIT T 9-2010 del JLT de Arica, de 18 de agosto de 2010, y RIT T 5-2010 del JLT de Calama, de 11 de agosto de 2010.

18 Podemos citar las sentencias recaídas en las causas RIT T 11-2010 del 1er JLT de Santiago, de 7 de abril de 2010; RIT T 1-2010 del JLT de Punta Arenas, de 30 de julio de 2010, y rol 7-2010 de la Iltma. Corte de Apelaciones de Coyhaique, de 18 de mayo de 2010 .

19 Sentencia del JLT de San Miguel, en causa RIT T 48-2011, de 7 de mayo de 2012.
} 
sor Eduardo Aldunate al hablar de la distinción entre derecho y garantía, en el sentido que actualmente se vincula a tal punto la idea del derecho reconocido con la necesidad de su protección (la garantía) que "si en un ordenamiento jurídico un derecho no tiene reconocimiento o, si teniendo reconocimiento carece de alguna vía para obtener su protección, se puede llegar a discutir su carácter de tal derecho" 20 .

No es una cuestión fácil la elaboración conceptual de la distinción entre derecho y garantía. Peces-Barba señala que los mecanismos de protección de derechos son los que le otorgan a estos su nota de resistencia frente a otros poderes, la que, a su vez, da el carácter de fundamental al derecho dentro del ordenamiento e identifica la noción de garantía con cualquier elemento del ordenamiento jurídico y político susceptible de contribuir a la vigencia efectiva de los derechos fundamentales ${ }^{21}$, en otras palabras, la garantía se constituye en una herramienta para la vigencia efectiva de los derechos.

Luigi Ferrajoli, por su parte, realiza una distinción entre derecho y garantía, señalando que corresponde llamar "garantía" a toda obligación correspondiente a un derecho subjetivo, entendiendo por "derecho subjetivo" toda expectativa jurídica positiva (de prestaciones) o negativa (de no lesiones). Acto seguido, hace la diferencia entre garantías positivas y garantías negativas, las "garantías positivas" consistirían en la obligación de la comisión, en tanto que las "garantías negativas" en la obligación de la omisión (es decir, en la prohibición) del comportamiento que es contenido de la expectativa o derecho. Finalmente, Ferrajoli realiza una segunda distinción en materia de garantías, llamando "garantías primarias o substanciales" a las garantías consistentes en las obligaciones o prohibiciones que corresponden a los derechos subjetivos garantizados, por un lado, y, por otro, denominando "garantías secundarias o jurisdiccionales" a las obligaciones, por parte de los órganos judiciales, de aplicar la sanción o de declarar la nulidad cuando se constaten actos ilícitos o actos no válidos que violen los derechos subjetivos $\mathrm{y}$, con ellos, sus correspondientes garantías primarias $^{22}$.

A pesar de las críticas que se han hecho a esta distinción ${ }^{23}$, ella nos parece bastante clara y precisa y llevada a nuestra realidad jurídico-laboral, y más específicamente a la norma del artículo 485 inciso tercero del Código del Trabajo, podemos afirmar que lo que allí se establece corresponde más bien a un derecho subjetivo de carácter negativo, esto es, el derecho del trabajador a no ser objeto de represalias por parte de su empleador en el ejercicio legítimo de acciones judiciales o de gestiones administrativas ante el organismo fiscalizador laboral.

Este derecho a no ser objeto de represalias está dotado de sus correspondientes garantías, tanto primarias como secundarias, en el lenguaje de Ferrajoli. En efecto, la garantía

\footnotetext{
20 Aldunate Lizana, Eduardo. Derechos Fundamentales. Santiago, Chile: LegalPublishing, 2008, p. 79.

21 Ibid, p. 80.

22 Ferrajoli, Luigi. Democracia y Garantismo. Madrid, España: Trotta, 2008, pp. 63-64.

23 Una de las críticas más interesantes que se han dirigido a esta tesis de Ferrajoli es la elaborada por Riccardo Guastini en su ensayo titulado "Tres problemas para Luigi Ferrajoli". En: AA. VV. Los fundamentos de los derechos fundamentales. Madrid, España: Trotta, 2009, pp. 57-62. En este trabajo, Guastini cuestiona la definición de derecho subjetivo como una expectativa a la que corresponde una obligación y señala que si el concepto de obligación correspondiente es definitorio del concepto de derecho subjetivo, entonces no existiría derecho subjetivo sin obligación correspondiente.
} 
primaria o substancial consiste específicamente en la prohibición que tiene el empleador de ejercer represalias en contra de sus trabajadores, en razón o como consecuencia de la labor fiscalizadora de la Dirección del Trabajo o por el ejercicio de acciones judiciales.

Y entonces ¿cuál sería la garantía secundaria del derecho de indemnidad? Bueno, como dijimos, Ferrajoli define la garantía secundaria o jurisdiccional como las obligaciones de los órganos jurisdiccionales de aplicar sanciones o de declarar la nulidad cuando se constaten actos ilícitos o actos no válidos que violen los derechos subjetivos y, con ellos, sus correspondientes garantías primarias. De esta forma, tratándose del derecho de indemnidad, la garantía secundaria consiste precisamente en la acción que tiene el trabajador que ha sido vulnerado en su derecho para recurrir al procedimiento de tutela laboral y solicitar que el empleador que ejerció la represalia sea sancionado, de conformidad a la ley.

Creemos que seguir con la tendencia mayoritaria hasta hoy (pero no unánime), tanto en la doctrina como la jurisprudencia, de utilizar la expresión "garantía de indemnidad" para referirse al derecho contemplado en el artículo 485 inciso tercero del Código del Trabajo, constituye un error y solamente obedece a la idea de importar el lenguaje y la fundamentación originada en el sistema jurídico español, cuando obviamente este tiene importantes diferencias con el nuestro en materia de derecho de indemnidad. Por ello, en lo sucesivo hablaremos simplemente de "derecho de indemnidad".

Esto nos lleva, además, a proponer una definición propia del derecho de indemnidad dentro de nuestro sistema jurídico laboral. Así, creemos que podríamos definir el derecho de indemnidad como "aquel derecho que tienen los trabajadores a no ser objeto de represalias por parte de su empleador, en razón o como consecuencia del ejercicio de acciones judiciales o de la labor fiscalizadora de la autoridad administrativa laboral".

\section{ELEMENTOS DEL DERECHO DE INDEMNIDAD}

De la definición entregada se deriva con claridad que en nuestro sistema son tres los elementos o componentes en los que el derecho de indemnidad se desglosa, a saber: 1) el ejercicio de una acción judicial o la labor fiscalizadora de la Dirección del Trabajo; 2) la represalia por parte del empleador, y 3) la conexión causal o vínculo de causalidad entre ambas conductas.

\subsection{EJERCICIO DE ACCIÓN JUdICIAL O LABOR FISCALIZADORA DE LA DiRECCIÓN DEL TRABAJO \\ Con relación a este elemento, el análisis lo haremos en forma separada respecto de} cada uno de sus dos supuestos:

\section{a) El ejercicio de acciones judiciales}

Respecto de este supuesto, el artículo 485 inciso tercero habla solo del "ejercicio de acciones judiciales", sin establecer ninguna limitación respecto de quien debió haber interpuesto dichas acciones judiciales, razón por la cual en nuestra opinión no es menester que sea el propio trabajador afectado por la represalia quien haya deducido la acción judicial, sino que puede haber accionado otro trabajador u otra entidad como, por ejemplo, una organización sindical. 
Por otro lado, el derecho de indemnidad opera con independencia del órgano jurisdiccional requerido y del tipo de acción ejercida judicialmente por el $\operatorname{trabajador}^{24}$ o por la entidad respectiva, puesto que la norma del artículo 485 inciso tercero del Código del Trabajo solo habla de "acciones judiciales" y no parece que pueda diferenciarse respecto del carácter laboral o no laboral de la acción deducida. Así, el derecho de indemnidad también será aplicable, por ejemplo, cuando se trate de represalias por el ejercicio de acciones penales contra el empleador o alguna de las personas que lo representan, según la presunción del artículo $4^{\circ}$ inciso primero del Código del Trabajo.

Junto con ello, la redacción de la norma no exige que la reacción empresarial vaya ligada al resultado del proceso, a su éxito o fracaso, ya que lo pretendido por el derecho de indemnidad es evitar cualquier maniobra empresarial encaminada a impedir, coartar o castigar el ejercicio por el trabajador de una acción judicial, con independencia, incluso, de que el trabajador se desistiera en algún momento del procedimiento iniciado o de que dicha acción haya sido rechazada por falta de fundamento.

Cabe agregar que el ámbito de protección del derecho de indemnidad no solo abarca el ejercicio de acciones judiciales propiamente tales, sino que también a los actos preparatorios o previos al proceso, como una medida o gestión prejudicial o la denuncia interpuesta en contra del empleador en las oficinas del Ministerio Público, por ejemplo, tratándose de materia penal.

Un punto interesante en este tema lo constituye la situación del trabajador que interviene como testigo en un proceso judicial contra su empleador y que, a consecuencia de ello, es objeto de represalias. En nuestra opinión, no cabe duda que en ese caso también ese trabajador podría interponer una denuncia por vulneración del derecho de indemnidad, ya que la redacción del artículo 485 inciso tercero del Código del Trabajo señala "por el ejercicio de acciones judiciales”, en forma amplia, sin exigir ni establecer restricciones adicionales como podría ser, por ejemplo, que se trata de acciones judiciales ejercidas por el propio trabajador afectado por la represalia del empleador. En este sentido se pronunció el Juzgado de Letras del Trabajo de La Serena, en sentencia causa RIT T 13-2009, de fecha 14 de octubre de 2009, en la cual la denunciante era una trabajadora que fue despedida luego de haber prestado declaración como testigo en otro juicio laboral seguido en contra de su empleadora $\mathrm{y}$ en el cual esta última fue condenada.

En España, en cambio, el Tribunal Constitucional ha ideado una solución distinta, pero que lleva al mismo resultado, ya que la declaración testifical no es, en rigor, ejercicio de la acción judicial del trabajador afectado y, por lo tanto, no constituye una manifestación del derecho a la tutela judicial efectiva. Sin embargo, eso no significa que el trabajador que testifica quede desamparado, pues el Tribunal Constitucional español ha afirmado que también existe una garantía de indemnidad del testigo, si bien esta garantía no se deriva del derecho a la tutela judicial efectiva, sino del derecho a comunicar información veraz del artículo 20.1.d) de la Constitución española ${ }^{25}$.

24 En la causa RIT T 11-2010, del 1 er JLT de Santiago, la acción judicial deducida por la trabajadora denunciante había consistido en una demanda de indemnización de perjuicios motivada por un accidente del trabajo acaecido en la empresa.

25 Álvarez Alonso, Diego, op. cit. (n. 3), p. 64. 


\section{b) La labor fiscalizadora de la Dirección del Trabajo}

Este punto es de máxima relevancia en materia de derecho de indemnidad, ya que, hasta la fecha, de las denuncias interpuestas en el procedimiento de tutela laboral por esta causa, la gran mayoría tiene como antecedente alguna gestión o actuación referida a la Dirección del Trabajo en cuanto entidad fiscalizadora, la que sería precisamente la razón de la represalia del empleador ${ }^{26}$. Como contrapartida, podemos afirmar que las denuncias por infracción al derecho de indemnidad fundadas en una represalia que tenga como antecedente una acción judicial del trabajador, constituyen claramente una situación excepcional en nuestro sistema jurídico laboral.

En cuanto a la labor fiscalizadora de la mencionada institución, la Circular No 88 de la Dirección del Trabajo, de 5 de julio de 2001, que establece el Manual de Procedimientos de Fiscalización de dicho servicio, dispone que la fiscalización podrá ser ordinaria o informativa. La fiscalización ordinaria, o fiscalización propiamente tal, podrá ser, a su vez, "solicitada" o "de oficio". La fiscalización "solicitada" es aquella que tiene su origen en una petición realizada por los interesados, directamente a la Dirección del Trabajo o a otras reparticiones públicas las cuales transmiten dicha solicitud a ese servicio, o por cualquier persona o entidad. La fiscalización "de oficio", por su parte, es aquella que se realiza por disposición propia de la Dirección del Trabajo en cumplimiento de sus objetivos institucionales, normalmente por decisión de la propia unidad operativa o por determinación de la superioridad de dicha institución.

En nuestra opinión, el derecho de indemnidad en Chile comprende tanto las actuaciones fiscalizadoras "solicitadas" realizadas por la Dirección del Trabajo, esto es, aquellas que se originan en una denuncia hecha por el trabajador afectado o por otra persona o entidad, como también las fiscalizaciones "de oficio" que realiza esta institución por propia iniciativa, a partir de los programas de fiscalización que dicho servicio planifica y ejecuta.

Esto lleva a que el ámbito de protección del derecho de indemnidad en Chile sea bastante amplio, ya que no solo comprende las represalias del empleador ante las acciones judiciales y las gestiones administrativas del trabajador, sino que también las represalias ejercidas en contra de trabajadores cuando ni siquiera ha mediado gestión administrativa alguna por parte de estos. En este último caso, la intencionalidad o ánimo lesivo del empleador se habrá originado a partir de una actuación inspectiva que la Dirección del Trabajo definió por propia iniciativa, como puede ser, por ejemplo, un programa sectorial de fiscalización que implementó esta institución y que incluyó aleatoriamente a la empresa donde se verificó posteriormente la represalia en contra de uno o más trabajadores.

Adicionalmente, la labor fiscalizadora de la Dirección del Trabajo no solo se puede materializar a través de la fiscalización en terreno, sino que existen en dicha institución otras líneas de trabajo, como la mediación laboral, la que, junto con generar espacios de diálogo para abordar el conflicto, también persigue obtener el cumplimiento de la normativa laboral. Aparece de toda lógica y no contraría el sentido del artículo 485 inciso tercero del Código del Trabajo, que una medida de represalia por parte del empleador que tenga su origen

\footnotetext{
26 Como antecedente, podemos señalar que de las 40 sentencias judiciales referidas al derecho de indemnidad que hemos tenido a la vista en la elaboración del presente trabajo, en 37 de ellas la eventual represalia tenía como causa la labor fiscalizadora de la Dirección del Trabajo.
} 
en una mediación realizada por la Dirección del Trabajo, también haga procedente la acción de tutela laboral fundada en la vulneración del derecho de indemnidad.

\subsection{REPRESALIA DEL EMPLEADOR}

Lo primero que cabe señalar en este punto es que existe una multiplicidad de formas que puede revestir la conducta de represalia del empleador, y ello tiene su origen precisamente en el carácter igualmente amplio y variado de las facultades integrantes de los poderes

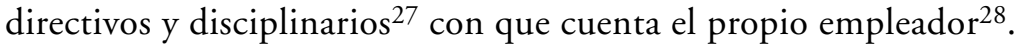

La doctrina española ha señalado que son dos los elementos caracterizadores del comportamiento empresarial en materia de Garantía de Indemnidad, los cuales son: la intencionalidad o ánimo lesivo, por una parte, y el perjuicio causado al trabajador, por otra ${ }^{29}$.

En nuestro país, y en términos concretos, la medida de represalia utilizada en la gran mayoría de los casos por el empleador ha sido el despido ${ }^{30}$, pero también pueden existir casos en que la medida que se adopte sea otra distinta del despido, tales como el traslado, la sanción disciplinaria, el cambio de funciones, modificaciones substanciales en las condiciones de trabajo, el cese en el abono de un determinado incentivo salarial, decisiones sobre ascensos, etc. Algunas de estas medidas podrían ser consideradas también como parte de un proceso de hostigamiento laboral, mobbing o acoso moral en el trabajo ${ }^{31}$, definido por la doctrina nacional como aquel:

"proceso conformado por un conjunto de acciones u omisiones, en el ámbito de las relaciones laborales públicas y privadas, en virtud de las cuales uno o más sujetos acosadores crean un ambiente laboral hostil e intimidatorio respecto de uno o más acosados, afectando gravemente su dignidad personal y dañando la salud del o los afectados con miras a lograr distintos fines de tipo persecutorio" 32 .

\footnotetext{
27 IgARTUA Miró, María Teresa, op. cit. (n. 7), p. 103.
}

28 La Dirección del Trabajo, en su dictamen no 2856/162, de 30 de agosto de 2002, definió el poder de dirección del empleador como "una serie de facultades o prerrogativas que tienen por objeto el logro del referido proyecto empresarial en lo que al ámbito laboral se refiere, y que se traducen en la libertad para contratar trabajadores, ordenar las prestaciones laborales, adaptarse a las necesidades de mercado, controlar el cumplimiento y ejecución del trabajo convenido, y sancionar las faltas o los incumplimientos contractuales del trabajador".

29 CASAS BaAmonde, María Emilia. Tutela judicial efectiva y garantía de indemnidad. En: AA.VV. Las transformaciones del Derecho del Trabajo en el marco de la Constitución Española. Madrid, España: La Ley, 2006, p. 720.

30 De las 40 sentencias analizadas para el presente trabajo, en 38 la medida de represalia denunciada consistía en el despido del trabajador o trabajadores denunciante(s).

31 Así también lo han reconocido nuestros tribunales laborales. Podemos citar en esta línea la sentencia pronunciada en causa RIT T 13-2011 del JLT de Valdivia, de fecha 15 de diciembre de 2011, que en su considerando quinto señala: "De lo razonado en los considerandos precedentes y acorde las reglas de la sana crítica, es posible concluir que el despido intempestivo del trabajador no fue sino una represalia por el reclamo de éste ante el dueño de la empresa, del actuar del gerente y otros mandos de la misma y de la rebaja de remuneraciones y de cargo o funciones, siendo, como sostiene el actor, la culminación de un proceso de hostigamiento laboral".

32 Gamonal Contreras, Sergio; Prado López, Pamela. El mobbing o acoso moral laboral. Santiago, Chile: LegalPublishing, 2009 , pp. 22-23. Por su parte, la ley 20.607, publicada en el Diario Oficial de 8 de agosto de 2012, define acoso laboral como "toda conducta que constituya agresión u hostigamiento reiterados, ejercida por el empleador o por uno o más trabajadores, en contra de otro u otros trabajadores, por cualquier medio, y que tenga como resultado para el o los afectados su menoscabo, maltrato o humillación, o bien, que amenace o perjudique su situación laboral o sus oportunidades en el empleo". 
Obviamente un análisis específico del mobbing o acoso moral laboral excede los objetivos de este trabajo. Como ejemplo de denuncia de una medida de represalia distinta del despido, podemos identificar la sentencia en la causa Rol 31-2010, de 29 de abril de 2010, de la Iltma. Corte de Apelaciones de Valdivia, en que la supuesta medida de represalia denunciada consistía en la rebaja unilateral de la carga académica de un docente, no obstante que la Corte estimó que en ese caso específico dicha medida no constituía un acto de represalia que afectara el derecho de indemnidad laboral.

En cuanto al despido como medida de represalia del empleador, a la vez que la más utilizada, ella constituye la medida más dura y la más obvia, y respecto de la cual existen más herramientas para combatir jurídicamente ya que, además de la garantía de indemnidad, en subsidio, existen las normas del propio Código del Trabajo sobre despido injustificado, indebido o improcedente. Las represalias también pueden tener lugar en el contexto de un despido colectivo, al momento de definir los trabajadores que van a resultar afectados por la medida de desvinculación, mediante la inclusión preferente en la nómina de aquellos que hubieren litigado contra la empresa o que hubieren presentado una denuncia en la Inspección del Trabajo, en lugar de otros trabajadores en su misma situación pero menos conflictivos a juicio del empleador.

Un caso especial lo constituye la no renovación del contrato a plazo fijo, caso en el cual habrá que considerar si ha existido o no discriminación respecto de los trabajadores cuyo contrato a plazo fijo venció y no se les renovó, respecto de los demás trabajadores en igual situación, provocada por alguna gestión realizada por ellos ante la Inspección del Trabajo o por el ejercicio de alguna acción judicial ${ }^{33}$. En este caso, además, será imprescindible acreditar la intencionalidad o ánimo lesivo del empleador, tanto más cuanto que en la inmensa mayoría de los casos el empleador no estará obligado legalmente a renovar un contrato a plazo fijo.

\subsection{CONEXIÓN CAUSAL O VÍNCULO DE CAUSALIDAD}

En tercer lugar, va a ser determinante respecto del derecho de indemnidad, el vínculo de causalidad existente entre el ejercicio de una acción judicial o la labor fiscalizadora de la Dirección del Trabajo, por una parte, y la conducta o medida de represalia del empleador, por otra. Así se desprende del tenor literal del artículo 485 inciso tercero del Código del Trabajo, al utilizar las expresiones "en razón o como consecuencia" para hacer procedente la garantía de indemnidad.

Si concurre esta relación causa-efecto, entra en juego el derecho de indemnidad haciendo procedente la respectiva denuncia por vulneración del mismo y la correspondiente sentencia condenatoria. Por el contrario, si ese enlace no queda suficientemente demostrado, no tendrá éxito la correspondiente denuncia. De esta forma, el vínculo o conexión causal se sitúa en el centro de todo juicio en que se invoque el derecho de indemnidad, puesto que la acreditación de la existencia de dicho vínculo determina el resultado del proceso.

\footnotetext{
33 Específicamente sobre la no renovación de contratos a plazo fijo, existe una sentencia del Juzgado de Letras del Trabajo de Arica, en causa RIT T 9-2010, de 18 de agosto de 2010, que rechaza la acción de tutela intentada, fundamentalmente debido a las debilidades encontradas por el sentenciador tanto en la relación de los hechos como en materia probatoria.
} 
Por otro lado, cabe tener en consideración que no toda conexión más o menos genérica entre el acceso a la jurisdicción o la labor fiscalizadora de la Dirección del Trabajo y la posterior conducta o medida del empleador, resultará suficiente para que se entienda infringido el derecho de indemnidad. En efecto, es necesario que el ejercicio de la acción judicial o que la labor fiscalizadora del ente administrativo ya señalado, sean el detonante inmediato y directo de la actuación del empleador, esto es, que exista una conexión íntima y estrecha entre la decisión de la empresa y el ejercicio de una acción judicial o el desarrollo de labores inspectivas o fiscalizadoras por parte de la Dirección del Trabajo, para que pueda afirmarse que existe una lesión del derecho de indemnidad. En pocas palabras, que la decisión del empleador es consecuencia directa de la acción judicial o de las labores fiscalizadores de la autoridad administrativa laboral. Así lo han señalado nuestros tribunales del trabajo, por ejemplo, en la sentencia de la causa RIT T 53-2009 del JLT de Valparaíso, de 19 de febrero de 2010, que dispone "resulta del todo insuficiente para establecer que haya existido un actuar tendiente a ocasionar daño al trabajador, sobre todo porque no se divisa la conexión causa-efecto entre estos hechos, en circunstancias que una represalia necesariamente debe ser respuesta o reacción directa, lo que no se dio en la especie".

Como debe existir este vínculo íntimo y estrecho, dicha relación no se daría si no se prueba, al menos, el conocimiento por parte de la empresa del ejercicio de una acción judicial o de las labores fiscalizadoras emprendidas por la Dirección del Trabajo. No obstante, la apreciación por parte del tribunal de la relación causal y, en definitiva, de la vulneración del derecho de indemnidad, va a aparecer muy apegada a las circunstancias del caso concreto, de forma tal que nos hallamos ante una cuestión eminentemente casuística.

La actividad probatoria no planteará demasiados problemas para el denunciante cuando esta conexión se manifieste explícitamente en la propia carta de despido o en otro documento $^{34}$, o se haga evidente de cualquier otra forma. Pero esto obviamente no será lo más habitual, ya que lo más frecuente es que la medida de represalia se presente justificada aparentemente con otro tipo de razones, algo que es habitual en los supuestos de vulneración de derechos fundamentales en general, y para lo cual el legislador estableció la regla probatoria de indicios, contemplada en el artículo 493 del Código del Trabajo y a la cual nos referimos a continuación.

\section{DERECHO DE INDEMNIDAD Y PRUEBA INDICIARIA}

\subsection{LA CENTRALIDAD DE LA PRUEBA INDICIARIA EN MATERIA DE DERECHO DE INDEM- NIDAD}

En cuanto al desarrollo del proceso de tutela laboral, y específicamente en materia probatoria, cabe resaltar el papel central que en los juicios por vulneración del derecho de indemnidad le ha correspondido a la institución conocida como "prueba indiciaria", establecida en nuestro ordenamiento en el artículo 493 del Código del Trabajo, la que opera como

\footnotetext{
34 Así, por ejemplo, en la causa RIT T 44-2010, del $1^{\text {er }}$ JLT de Santiago, se acompañó como prueba documental el acta del comparendo de conciliación ante la Inspección del Trabajo, donde la empleadora denunciada afirma como fundamento del término de la relación laboral, entre otros, "menoscabo a los empleadores, realizando denuncias a las Inspecciones del Trabajo con la sola intención de provocar daño, menoscabar la actividad laboral de su empleador”.
} 
una verdadera garantía procesal que actúa sobre el onus probandi (carga de la prueba), en tanto lo facilita en un ámbito en donde la posibilidad de allegar prueba de una vulneración resulta particularmente difícil para la persona del trabajador afectado, debido normalmente al ocultamiento o encubrimiento de la verdadera causa vulneratoria ${ }^{35}$.

La prueba indiciaria, en cuanto técnica probatoria, se ha venido a justificar tradicionalmente tanto en la prevalencia de los derechos fundamentales como en las especiales dificultades probatorias ${ }^{36}$ y, por ello, responde en último término a la necesidad de reequilibrar la posición de inicial desigualdad de la parte denunciante, remediando las dificultades probatorias para llevar a la convicción al órgano jurisdiccional sobre la existencia de la conducta vulneratoria del derecho fundamental cuya eliminación se pretende.

Si bien esta técnica probatoria está pensada originalmente para superar las dificultades del trabajador para demostrar el hecho lesivo, la exigencia al denunciante de aportar antecedentes que constituyan un principio de prueba de la afección del derecho o garantía también podría servir para evitar que se presenten denuncias totalmente infundadas, constituyendo una suerte de finalidad secundaria de la institución.

En nuestro Código del Trabajo, el artículo 493 dispone al efecto que "Cuando de los antecedentes aportados por la parte denunciante resulten indicios suficientes de que se ha producido la vulneración de derechos fundamentales, corresponderá al denunciado explicar los fundamentos de las medidas adoptadas y de su proporcionalidad".

De esta forma, la norma citada establece una operación técnica de debilitamiento de la carga probatoria, de alteración de la carga de la prueba, cuando concurren indicios aportados por el denunciante respecto de la afectación o vulneración de derechos fundamentales, de forma tal que se desplaza la carga de la prueba al empleador denunciado, quien deberá acreditar y explicar la proporcionalidad y los fundamentos de la medida objeto de la denuncia que, en el caso del derecho de indemnidad, consistirá específicamente en la medida considerada eventualmente como represalia contra el trabajador (despido, traslado, cambio de condiciones de trabajo, etc.).

Tal como señala el profesor Christian Melis, "no se trata propiamente de una inversión de la carga de la prueba, ya que siempre toca al denunciante aportar los indicios exigidos por la norma" 37 . Se trata, en definitiva, de un principio de prueba cuyo fin no es servir a formar de manera plena la convicción del juez sobre la ocurrencia de la vulneración, sino más bien inducir a una creencia racional de la probabilidad real de un cierto clima vulnerador del derecho fundamental de que se trata a través de la medida que se impugna.

Ahora bien, a pesar de la regla de la prueba indiciaria, la actividad probatoria de las partes en el procedimiento de tutela laboral no tiene variaciones formales respecto de otros procedimientos laborales. En efecto, "las reglas sobre la carga formal de la prueba (quién

\footnotetext{
35 Baylos Grau, Antonio. Medios de prueba y derechos fundamentales. Especial referencia a la tutela de estos derechos. Madrid, España, 1998, p. 27. Citado por Melis VALENCIA, Christian. Los Derechos Fundamentales de los Trabajadores como limites a los poderes empresariales. Santiago, Chile: LegalPublishing, 2009, p. 74.

36 Monereo Pérez, José Luis. La carga de la prueba en los despidos lesivos de los derechos fundamentales. Valencia, España: Tirant lo Blanch, 1996, p. 9.

37 Melis Valencia, Christian, op. cit. (n. 35), p. 76.
} 
debe probar) y los medios de prueba (cómo se debe probar) son las mismas que las previstas para el procedimiento de aplicación general" 38 .

La doctrina española sobre la prueba indiciaria, especialmente contenida en los fallos del Tribunal Constitucional, ya que la regla de indicios en dicho país también ha sido una creación jurisprudencial, ha señalado que esta técnica probatoria está conformada por dos elementos: los indicios suficientes a cargo del demandante, por una parte, y la prueba liberatoria a cargo del empleador demandado, por otra ${ }^{39}$.

Con relación a la aportación de indicios suficientes, la actividad probatoria que correspondería al denunciante consiste básicamente en probar dos extremos de suma importancia: de un lado, una situación fáctica que evidencia un trato desigual o un flagrante desconocimiento de sus derechos y, de otro, la vinculación en el caso concreto entre dicha situación fáctica y uno o varios derechos fundamentales ${ }^{40}$. Específicamente respecto de la garantía de indemnidad en nuestro sistema jurídico-laboral, el denunciante deberá, en primer término, proporcionar antecedentes suficientes sobre la adopción de una medida por parte del empleador en uso de sus facultades directivas y disciplinarias (despido, traslado, cambio de funciones, etc.) y, en segundo término, aportar antecedentes de que esa medida se ha adoptado como represalia en razón o como consecuencia de la labor fiscalizadora de la Dirección del Trabajo o por el ejercicio de alguna acción judicial.

En cuanto a la prueba liberatoria del empleador, esta actividad probatoria entra en juego solo y exclusivamente cuando efectivamente el primer elemento descrito (la aportación de indicios suficientes) haya quedado cubierto. Esta actividad del empleador, en materia de derecho de indemnidad, deberá estar encaminada a probar la concurrencia de una motivación real y consistente, no constitutiva de represalia, para su conducta o medida, capaz de destruir aquella apariencia o duda que el denunciante ha generado en el juzgador. En síntesis, lo que se le está pidiendo al empleador es que destruya "la verdad interina que el demandante ha creado con sus alegaciones" ${ }^{41}$.

No creemos que en materia de derecho de indemnidad corresponda al empleador denunciado explicar la proporcionalidad de las medidas adoptadas, ya que no es posible concebir racionalmente medidas de represalia adoptadas por el empleador, ya sea en razón o como consecuencia de la labor fiscalizadora de la Dirección del Trabajo o por el ejercicio de acciones judiciales, que sean "proporcionales". En este punto tendemos a coincidir con el profesor José Luis Ugarte en el sentido que "nunca hay represalias justificadas o proporcionadas" 42 .

Lo anterior significa que una vez establecido por el trabajador el indicio suficiente de la existencia de una medida adoptada por el empleador y que esta tendría el carácter de una represalia en los términos del artículo 485 inciso tercero del Código del Trabajo, al emplea-

\footnotetext{
38 Ugarte CATAldo, José Luis. "Tutela laboral de derechos fundamentales y carga de la prueba", en: Revista de Derecho de la Pontificia Universidad Católica de Valparaíso XXXIII, Valparaíso, Chile, 2o semestre de 2009, p. 220.

39 IgARTUA Miró, María Teresa, op. cit. (n. 7), p. 114.

$40 \quad$ Ibid, p. 117.

41 Baylos GraU, Antonio et al. Instituciones de Derecho Procesal Laboral. Madrid, España: Trotta, 1995, p. 171.

42 Ugarte Cataldo, José Luis, Tutela de derechos... (n. 12), p. 37.
} 
dor solo le corresponde como prueba liberatoria acreditar la concurrencia de una motivación real para dicha medida, esto es, demostrar que la medida resulta totalmente ajena a un móvil discriminatorio o contrario a derechos fundamentales que tenga su base en la labor fiscalizadora de la Dirección del Trabajo o en el ejercicio de alguna acción judicial, lo que significa, en concreto, que dicha medida no constituye una represalia contra el trabajador.

Finalmente, en esta parte, cabe pronunciarse respecto del temor que pueden tener algunos sobre la posibilidad de un uso torcido del derecho de indemnidad por parte de aquellos trabajadores que, sabiéndose en una situación comprometida en la empresa, intentaran manipular esta institución para tratar de "asegurar" o "blindar" su situación laboral ante un probable despido. Para ello, dichos trabajadores supuestamente optarían por presentar alguna denuncia o realizar otra actuación ante la Inspección del Trabajo que, aunque no prosperara o fuere infundada, les serviría como medio de defensa frente a una eventual desvinculación por parte del empleador, la que sería inmediatamente tachada de represalia gatillada por aquella actuación ante la Inspección y los habilitaría para deducir la acción de tutela laboral.

En nuestra opinión este temor es infundado, básicamente por dos razones. En primer término, se debe señalar que en los cuatro años que lleva utilizándose el procedimiento de tutela laboral en Chile no se ha advertido este fenómeno, precisamente porque la necesidad del denunciante de aportar antecedentes de los que resulten indicios suficientes de que se ha producido la vulneración, ha llevado en términos generales a una utilización responsable del derecho de indemnidad por parte de los trabajadores. En segundo lugar, en cuanto al papel que le corresponde al empleador en materia de derecho de indemnidad, si efectivamente existe una causa legal en virtud de la cual poner término a la relación laboral, la demostración de los hechos en que se funda la causal le podría bastar en principio al empleador para "destruir" la pretendida relación de causalidad entre la gestión realizada por el trabajador ante la Inspección del Trabajo y el despido, evitando así que se considere como una represalia.

\subsection{TENDENCIAS JURISPRUDENCIALES OBSERVADAS EN MATERIA DE DERECHO DE IN- DEMNIDAD Y PRUEBA INDICIARIA}

Señalada la centralidad de la prueba indiciaria en materia de derecho de indemnidad, resulta ahora pertinente hacer un pequeño recorrido por los principales indicios que los tribunales han considerado "suficientes" para propiciar la puesta en funcionamiento de la carga del empleador denunciado de "explicar los fundamentos de las medidas adoptadas y de su proporcionalidad". Considerando que puede admitirse como indicio cualquier elemento probatorio que pueda ayudar a formar la creencia judicial sobre la, al menos probable, existencia de una vulneración del derecho de indemnidad, no es tanta la variedad de indicios que pueden encontrarse en lo que va de aplicación del procedimiento de tutela laboral en nuestro país.

Cabe recordar en este punto que la gran mayoría de las denuncias de tutela laboral por vulneración del derecho de indemnidad, tienen como antecedente la labor fiscalizadora de la Dirección del Trabajo. Por ello, los indicios van a estar referidos principalmente a las actuaciones realizadas ante o por dicha institución fiscalizadora. 


\section{a) \\ La cercanía temporal entre la labor fiscalizadora de la Dirección del Trabajo y el despido} del trabajador, como indicio de la represalia del empleador

En primer término, el indicio con más frecuencia alegado en materia de derecho de indemnidad por los denunciantes y admitido por los tribunales, está constituido por la proximidad o cercanía temporal entre la denuncia del trabajador ante la Dirección del Trabajo o la fiscalización de dicha institución, por un lado, y la medida o decisión del empleador presuntamente constitutiva de represalia, por otro, lo que en la inmensa mayoría de los casos consiste en el despido del trabajador. Esta cercanía temporal o secuencia cronológica ha operado en la práctica como una regla determinante para ser considerada por los jueces como un indicio suficiente de que se ha producido la vulneración del derecho de indemnidad. En esta línea se pronunció la Iltma. Corte de Apelaciones de Rancagua, en sentencia dictada en causal Rol 102-2010, de 1 de septiembre de 2010, al señalar en uno de sus considerandos que "de los antecedentes reseñados en los motivos quinto a undécimo del fallo impugnado, es dable tener por acreditado que hay una secuencia cronológica entre la fiscalización verificada por la Inspección del Trabajo y el despido que dice haber sido objeto el trabajador". Otro fallo que podemos citar en este punto es el del JLT de Iquique, de 1 de septiembre de 2009, en causa RIT T 14-2009, donde se establece que "se aprecia una cercanía espacial entre la fecha de la fiscalización, es decir, el 22 de abril de 2009 y la fecha del despido, a saber, el 28 de abril de 2009, tal como da cuenta la correspondiente carta de despido, es decir, solo seis días después de realizada la actividad fiscalizadora, la empresa decide desvincular a la trabajadora" 43 .

No obstante lo recién afirmado, existen algunos casos, minoritarios, en que el propio tribunal ha afirmado que "la vulneración de este derecho no se configura exclusivamente con una constatación objetiva de proximidad temporal entre una de las hipótesis -acción fiscalizadora de la Dirección del Trabajo- y el despido, sino que además requiere que exista la represalia" 44 , o bien, que el artículo 493 del Código del Trabajo "exige la concurrencia de 2 o más indicios para alterar la obligación de probar" y que "haber establecido la concurrencia de tan solo un indicio, expresado en la correlación temporal entre el requerimiento de fiscalización ante la Inspección del Trabajo por parte del actor y su despido (...) viola el sentido y tenor del artículo 493 ya mencionado" 45 .

Pero ¿cuánto será el tiempo necesario para considerar que se configura esta cercanía o proximidad temporal entre la denuncia o fiscalización y el despido y, de esta forma, pueda ella ser considerada como un indicio suficiente de que se ha producido la vulneración del derecho de indemnidad? ¿5 días? ¿10 días? ¿1 mes? ¿6 meses? Obviamente en este punto no existe un criterio uniforme y es un tema que debe resolverse caso a caso, considerando los

\footnotetext{
43 En esta misma dirección, podemos citar además las sentencias de las causas rol 7-2010 de la Corte de Apelaciones de Coyhaique, de 18 de mayo de 2010; RIT T 4-2008, de 20 de febrero de 2009, y T 9-2009, de 14 de julio de 2009, ambas del JLT de Iquique; T4-2010 del JLT de La Serena, de fecha 29 de mayo de 2010; T 5-2009 del JLT de Valparaíso, de 6 de mayo de 2009; T 70-2010 del 20 JLT de Santiago, de 1 de septiembre de 2010, y T 1-2010 del Juzgado de Letras y Garantía de Litueche, de fecha 8 de octubre de 2010 .

44 Sentencia del JLT de Copiapó en causa RIT T5-2008, de 23 de febrero de 2009.

45 Sentencia de la Iltma. Corte de Apelaciones de Valdivia, en causa rol 41-2010, de fecha 7 de abril de 2010.
} 
demás antecedentes del proceso. Sin perjuicio de ello, existen algunas sentencias al respecto que, de alguna forma, nos entregan algunas señales sobre el punto.

Podemos citar el caso de un juicio en el que se rechazó la denuncia de tutela, entre otras razones, porque el juez consideró que "ocurrido el despido cuatro meses después este no puede considerarse como un indicio de proximidad temporal en la correlación de los hechos alegados" 46 . En otra causa, el tribunal determinó que "si bien es cierto que el actor realizó una denuncia ante la Inspección del Trabajo, ello fue en marzo de 2009, de manera que es absurdo sostener que el demandado haya esperado casi un año para cobrar venganza por esta situación y despedirlo" ${ }^{37}$. Finalmente, en una tercera, la jueza no estimó que los despidos correspondieran "a una reacción frente a la demanda interpuesta casi dos años antes, no parece un acto de represalia como consecuencia o venganza por dicha actuación judicial, por cuanto ha transcurrido mucho tiempo entre estos hechos" 48 .

Ahora bien, en cuanto a la importancia que la cercanía o proximidad temporal ha adquirido en materia de prueba indiciaria tratándose de derecho de indemnidad, cabe señalar que se corre el riesgo de que se comience a instaurar una práctica consistente en que el empleador, en un acto de autocontención, no reaccione de inmediato frente al trabajador y planifique de manera más pausada la represalia, dejando transcurrir un lapso temporal razonable entre la denuncia o la fiscalización de la Dirección del Trabajo y la medida de represalia que pretende adoptar, con lo cual no se cumpliría con la finalidad de la institución.

Como contrapartida, también podría instaurarse el criterio de que, no establecida por el denunciante la proximidad o cercanía temporal, no resulta procedente alegar la vulneración del derecho de indemnidad, lo que tampoco parece razonable. Por ambas razones, no resulta conveniente que la cercanía o proximidad temporal funcione en los hechos prácticamente como el único indicio suficiente de que se ha producido la vulneración del derecho de indemnidad.

En menor medida que la cercanía o proximidad temporal entre la denuncia o fiscalización y el despido, los tribunales en ocasiones también han considerado como indicios los hostigamientos y presiones por parte del empleador o el hecho de impedirle este al trabajador el acceso a la empresa. Podemos citar aquí, como ejemplo, la sentencia del JLT de Talca, en causa RIT 3-2010, de 21 de abril de 2010, que establece, entre otros, como indicio de vulneración del derecho de indemnidad el hecho que "a la demandante en la mañana del día 28 de octubre de 2009, no le fue posible ingresar a la galería de exposición de la casa de amigos del arte, ubicada en el primer piso, como tampoco pudo hacerlo en el octavo piso, por encontrarse sus puertas con las chapas cambiadas y no contar con las llaves que accedían a esas nuevas chapas" 49 .

\footnotetext{
46 Sentencia del JLT de Iquique, en causa RIT T 13-2010, de 6 de julio de 2010.

47 Sentencia del JLT de La Serena, en causa RIT T 8-2010, de 16 de junio de 2010.

48 Sentencia del JLT de Valparaíso, en causa RIT T 53-2009, de 19 de febrero de 2010.

49 Otros ejemplos similares los podemos encontrar en las sentencias de las causas RIT T 14-2009 del JLT de Iquique, de 1 de septiembre de 2009; T 5-2009 del JLT de Valparaíso, de 6 de mayo de 2009, y T 1-2009 del JLT de Chillán, de 6 de noviembre de 2009 .
} 


\section{b) En cuanto a la prueba liberatoria del empleador}

Con respecto a la prueba liberatoria del empleador, como ya sabemos, esta actividad probatoria entra en juego solo una vez que se ha aportado indicios suficientes, por parte del denunciante, de que se ha producido la vulneración del derecho de indemnidad, y tiene por finalidad explicar los fundamentos de las medidas adoptadas y acreditar que ellas no constituyen una represalia en contra del trabajador. Desde que se comenzó a aplicar el procedimiento de tutela laboral, las circunstancias que más han sido hechas valer por los empleadores denunciados en materia de derecho de indemnidad, como forma de explicar el fundamento de las medidas adoptadas, son la efectividad de la causal invocada al momento del despido, la negación del vínculo laboral con el trabajador denunciante y el desconocimiento de la denuncia que había realizado el trabajador ante la Inspección del Trabajo.

Respecto de la primera situación, esto es, que la causal del despido es efectiva y no constituye una represalia, los tribunales han considerado que la no acreditación de la causal por parte del empleador denunciado, constituye un antecedente a tener en cuenta que refuerza la idea de que ha existido una represalia y, por ende, una vulneración del derecho de indemnidad, ya que el empleador no logra comprobar los hechos que supuestamente fundaron su decisión de despedir. Esto se da tanto respecto de la causal de necesidades de la empresa del artículo 161 del Código del Trabajo, como respecto de las causales de caducidad del artículo 160 del mismo cuerpo legal.

En cuanto a la causal de necesidades de la empresa, podemos citar la sentencia de la Iltma. Corte de Apelaciones de Coyhaique, de 18 de mayo de 2010, en causa Rol 7-2010, que dispone que:

"habiéndose establecido la procedencia del artículo 493 del Código del Trabajo, puesto que el trabajador acreditó suficientemente los indicios que dicha norma precisa, de que se hubiere producido la vulneración de derechos fundamentales; (...) de manera que al regular la carga de la prueba, en el fundamento Décimo, de acuerdo a la citada disposición legal, ésta quedó de parte de la denunciada quien debió probar los fundamentos de las medidas adoptadas y su proporcionalidad, esto es, de concurrir los elementos necesarios para justificar el despido por necesidades de la empresa, lo que, bajo el análisis lógico y comparativo que realiza el Juez del grado, concluyó acertadamente en que la denunciada no probó dicha causal y menos su proporcionalidad".

Con relación a la causal del artículo 160 no 3 del Código del Trabajo, no concurrencia del trabajador a sus labores sin causa justificada, podemos citar la sentencia del JLT de Valparaíso, en causa RIT T 5-2009, de 6 de mayo de 2009, donde se señala:

“Teniendo presente que el demandado a juicio de esta sentenciadora no alcanzó, con la prueba rendida al efecto, a justificar suficientemente los hechos que a su turno fundaron su decisión de despedir, por cuanto, como se ha señalado precedentemente, ni los testimonios ni los documentos incorporados en la audiencia de juicio forman convicción respecto que las ausencias imputadas hubieran sido efectivas sino que más bien, impresionan como el resultado de un esfuerzo encaminado a revestir el despido 
que se decidió, de las formalidades necesarias para su fundamento tras el expediente de no permitir, el 08 de noviembre que el actor firmara el libro de asistencia, retirándolo del local el día anterior".

Incluso existen casos en que el tribunal ha desestimado la alegación de la causal establecida en el artículo $159 \mathrm{n}^{\circ} 1$ del Código del Trabajo, mutuo acuerdo de las partes, como en la sentencia recaída en la causa RIT T 48-2011, del JLT de San Miguel, de 7 de mayo de 2012, que en su considerando duodécimo señala textualmente:

"Que si bien la empleadora, con el mérito del documento antes señalado, argumenta que los servicios del actor habrían concluido por la causal contemplada en el artículo 159 No1 del Código del Trabajo, esto es mutuo acuerdo de las partes, dicha pretensión será desestimada por esta sentenciadora toda vez que de conformidad a lo dispuesto en el artículo 177 del Código del Trabajo, 'El finiquito, la renuncia y el mutuo acuerdo deberán constar por escrito. El instrumento respectivo que no fuere firmado por el interesado y por el presidente del sindicato o el delegado del personal o sindical respectivos, o que no fuere ratificado por el trabajador ante el inspector del trabajo, no podrá ser invocado por el empleador', en consecuencia, no cumpliendo el documento referido en lo que antecede con ninguna de las formalidades exigidas por la norma antes citadas, ciertamente, el mismo no puede ser invocado por la empleadora como justificativa del término de los servicios del trabajador.

Que, por otra, si bien el documento antes señalado aparece otorgado con fecha 30 de junio de 2011, la propia empleadora al contestar la demanda señala que el mismo fue suscrito con fecha 1 de julio de 2011, esto es, al día siguiente de la segunda fiscalización efectuada a la empleadora por la Inspección del Trabajo con ocasión de la denuncia formulada por el trabajador demandante con fecha 30 de junio, circunstancia esta que, ciertamente, es indiciaria de la vinculación existente entre el término de los servicios del actor y la acción fiscalizadora de la entidad antes señalada, motivada por las denuncias efectuadas por el demandante".

Cabe precisar en este punto que ni la acreditación de la causal del despido permite descartar absolutamente que este haya sido una represalia que vulnere el derecho de indemnidad, ni tampoco de su no acreditación se deriva automáticamente la afección al citado derecho. En efecto, como ya lo ha señalado algún fallo ${ }^{50}$, podría tratarse de un despido pluricausal, en el que concurren como causales para el término del contrato de trabajo una legal acreditada (por ejemplo, necesidades de la empresa) junto con una causal ilegal que afecta el derecho de indemnidad, sin que se haya justificado por el empleador la no lesividad de esta última.

En lo que dice relación con la alegación consistente en el desconocimiento del vínculo laboral, en los hechos esta se ha transformado en una suerte de "arma de doble filo" para los empleadores denunciados, ya que una vez tenida por el juez por acreditada la relación labo-

50 Sentencia del JLT de La Serena, en causa RIT T 13-2009, de 14 de octubre de 2009. 
ral con el trabajador denunciante, en la mayoría de los casos el hecho de que el empleador lo haya desconocido ayuda al sentenciador a formarse convicción sobre la existencia de la represalia, sobre todo cuando la denuncia del trabajador ante la Inspección del Trabajo había consistido precisamente en la no formalización de su contrato de trabajo por parte del empleador. Podemos en este punto citar, a modo de ejemplo, la sentencia del JLT de Iquique, en causa RIT T 4-2008, de 20 de febrero de 2009, que en su considerando décimo sexto dispone "Que como corolario de todo lo anterior, procede, a juicio de este juzgador, que, al haberse acreditado la existencia de la relación laboral y no existir evidencia alguna que dé cuenta de las razones que por las que se le puso término, se cancele la indemnización (...)"51.

Finalmente, en cuanto a la prueba liberatoria del empleador, cuando este ha argumentado el desconocimiento de la denuncia o actuación del trabajador ante la Inspección del Trabajo al momento de despedir, los tribunales han considerado que esta circunstancia debe ser acreditada debidamente, ya que no basta con la simple alegación de la ignorancia o desconocimiento. Un caso de simple alegación del desconocimiento por parte del empleador, sin acreditarlo, está en la sentencia de la causa RIT T 5-2009, del JLT de Valparaíso, de 6 de mayo de 2009, ya que el denunciado había alegado que "ignoraba que la fiscalización realizada por la Inspección del Trabajo fuera consecuencia de una denuncia por parte de sus trabajadores, puesto que es habitual que los fiscalizadores recorran los locales del Supermercado...”, argumento que no fue acogido por el tribunal. En sentido contrario, en la causa RIT T 7-2010 del JLT de Puerto Montt, cuya sentencia es de fecha 14 de junio de 2010, el empleador denunciado logró acreditar en el proceso que la decisión del despido se había tomado con anterioridad a la solicitud de fiscalización interpuesta en la Inspección del Trabajo por las trabajadoras denunciantes.

De esta forma, cuanto el trabajador denunciante ha aportado indicios suficientes de que ha existido una vulneración del derecho de indemnidad, al empleador no le ha bastado con una simple alegación sobre la existencia de una causal legal de despido, el desconocimiento del vínculo laboral o su ignorancia de la existencia de una denuncia ante la Inspección del Trabajo, sino que ha tenido que acreditar debidamente las circunstancias alegadas y, en definitiva, la inexistencia de un ánimo lesivo o de represalia en contra del trabajador.

\section{CONCLUSIONES}

En este trabajo nos hemos abocado al estudio del derecho de indemnidad laboral desde una perspectiva tanto doctrinaria como práctica, con referencia expresa a derecho comparado y a nuestro ordenamiento jurídico nacional. Este estudio lo hemos querido vincular con un aspecto novedoso del nuevo procedimiento de tutela laboral y que en la práctica ha tenido mucha importancia en los juicios por vulneración del derecho de indemnidad, cual es la técnica probatoria conocida como prueba indiciaria.

Como resultado de nuestro estudio, que se ha plasmado a través del desarrollo de este trabajo, podemos precisar las siguientes conclusiones de síntesis:

51 Sobre este punto, se pueden consultar además las sentencias RIT T 9-2009 del JLT de Iquique, de fecha 14 de julio de 2009, y T 3-2010 del JLT de Talca, de 21 de abril de 2010. 
1. Sin duda que el derecho de indemnidad es una institución relativamente reciente en nuestro sistema jurídico laboral, pero que se ha ido constituyendo paulatinamente, desde que comenzó a aplicarse en el país el año 2008, en una herramienta relevante y eficaz para proteger el ejercicio efectivo de sus derechos por parte de los trabajadores.

2. En opinión nuestra, dada las especiales características que tiene esta institución jurídica en nuestro país, estamos frente a un derecho y no precisamente frente a una garantía, por lo que corresponde hablar del "derecho de indemnidad" para referirse a la institución contemplada en el artículo 485 inciso tercero del Código del Trabajo.

3. El ejercicio de este derecho de indemnidad ha estado mayoritariamente referido a combatir aquellas medidas del empleador que constituyen represalias, motivadas por la realización de alguna gestión (casi siempre una denuncia o solicitud de fiscalización) por parte del trabajador ante la Dirección del Trabajo a través de sus unidades operativas, esto es, en las Inspecciones del Trabajo. El ejercicio del derecho de indemnidad a raíz de una represalia del empleador motivada por una acción judicial del trabajador, es todavía una figura claramente minoritaria y excepcional en nuestro sistema.

4. Según la información que nos proporcionan las causas en que se denuncia la vulneración del derecho de indemnidad, la medida de represalia más utilizada por el empleador la constituye el despido. Las demás medidas de represalia posibles (traslado, cambio de funciones, modificación de condiciones de trabajo, etc.) constituyen situaciones menos frecuentes, o bien, no han sido enfrentadas por los trabajadores a través de denuncias por el procedimiento de tutela laboral.

5. La relación que existe entre el derecho de indemnidad y la técnica probatoria conocida como "prueba indiciaria", constituye un aspecto determinante para la acreditación de que ha existido una vulneración de este derecho por parte del empleador. De no existir esta técnica probatoria, sería muy dificultoso para el trabajador acreditar la infracción del derecho de indemnidad, por las razones ya expuestas en este trabajo.

6. El indicio más considerado por nuestros tribunales laborales, y por las Cortes de Apelaciones en aquellos casos en que les ha correspondido conocer de estas materias, como suficiente para estimar que se ha producido la vulneración del derecho de indemnidad, está constituido por la cercanía o proximidad temporal entre la denuncia del trabajador o la fiscalización de la Inspección del Trabajo, por una parte, y el despido del trabajador o trabajadores, por otra. Los demás indicios considerados, principalmente hostigamientos y presiones de diverso tipo hechas al trabajador, ayudan a formarse convicción al tribunal una vez que ha sido establecida la cercanía temporal entre la denuncia o la fiscalización y el despido.

7. En materia de prueba indiciaria, tratándose del derecho de indemnidad, existe una relación importante entre la prueba liberatoria del empleador y la acreditación o no acreditación por parte de este de la causal invocada al momento de despedir, como elemento probatorio de que el despido no se realizó con ánimo lesivo o de represalia. La no acreditación de la causal de término de la relación laboral por parte del empleador denunciado, lleva mayoritariamente a los tribunales a considerar, unido esto a otros elementos o indicios, que el despido constituyó una medida de represalia del empleador. 


\section{BIBLIOGRAFÍA}

AA. VV. Los Fundamentos de los Derechos Fundamentales. Madrid, España: Trotta, 2009.

ACADemia Judicial De Chile. Manual de Juicio del Trabajo. Santiago, Chile: LOM, 2008.

Aldunate Lizana, Eduardo. Derechos Fundamentales. Santiago, Chile: LegalPublishing, 2008.

Álvarez Alonso, Diego. La garantía de indemnidad del trabajador frente a represalias empresariales. Albacete, España: Bomarzo, 2005.

Baylos GraU, Antonio y otros. Instituciones de Derecho Procesal Laboral. Madrid, España: Trotta, 1995.

Bronfman Vargas, Alan; Martínez Estay, José Ignacio; Núñez Poblete, Manuel. Constitución Política comentada, Parte Dogmática. Santiago, Chile: Abeledo Perrot, 2012.

CÁrCAmo Zamora, Ximena; NúNEez GonZÁlez, Cayetano. "La prueba indiciaria en el procedimiento de tutela laboral chileno", en: Revista Laboral Chilena no 204. Santiago, Chile, febrero-marzo 2012.

CASAS BAAMONDE, María Emilia. "Tutela judicial efectiva y garantía de indemnidad”, en AA.VV. Las transformaciones del Derecho del Trabajo en el marco de la Constitución Española. Madrid, España: La Ley, 2006.

Evans De la CuAdra, Enrique. Los Derechos Constitucionales. Tomo II. Santiago, Chile: Editorial Jurídica, 1999.

Ferrajoli, Luis. Democracia y Garantismo. Madrid, España: Trotta, 2008.

Ferrajoli, Luis. Derechos y garantías. La ley del más débil. Madrid, España: Trotta, 2009.

Gamonal Contreras, Sergio. El Procedimiento de Tutela de Derechos Laborales. Santiago, Chile: LegalPublishing, 2009.

Gamonal Contreras, Sergio; Prado León, Pamela. El mobbing o acoso moral laboral. Santiago, Chile: LegalPublishing, 2009.

GIL Y GIL, José Luis. Despido por represalia y garantía de indemnidad, en Revista Capital Humano, 189, Madrid, España, junio de 2005.

Guidi MogGIA, Caterina. "Consagración legal de la garantía de indemnidad en nuestro ordenamiento jurídico laboral”, en: Revista Estudios Laborales no 2. Santiago, Chile: LegalPublishing, 2008.

IgArtua Miró, María Teresa. La Garantía de Indemnidad en la Doctrina Social del Tribunal Constitucional. Madrid, España: Consejo Económico Social, 2008.

Martín Valverde, Antonio; Rodríguez-Sañudo Gutiérrez, Fermín; García Murcia, Joaquín, Derecho del Trabajo. Madrid, España: Tecnos, 2007.

MARTíneZ Fons, Daniel. "La interpretación extensiva del alcance de la garantía de indemnidad en las relaciones laborales. STC 16/2006, de 19 de enero de 2006”. (Consultada el 12.12.2011 en sitio web www.upf. edu/iuslabor/022006/STC16-2006.pdf )

Melis ValenCIA, Christian. Los Derechos Fundamentales de los trabajadores como limites a los poderes empresariales. Santiago, Chile: LegalPublishing, 2009.

Ministerio de Justicia de Chile, Unidad de Defensa Laboral. “Tutela por Garantía de Indemnidad”, en: Estudios Laborales, no 7, Santiago, Chile, febrero, 2011.

Monereo Pérez, José Luis. La carga de la prueba en los despidos lesivos de los derechos fundamentales. Valencia, España: Tirant lo Blanch, 1996.

Orellana TORRes, Fernando. Comentarios al nuevo proceso laboral. Santiago, Chile: Librotecnia, 2008.

Ugarte Cataldo, José Luis. Tutela de derechos fundamentales del trabajador. Santiago, Chile: LegalPublishing, 2009.

UGARTE CATAldo, José Luis. "Tutela laboral de derechos fundamentales y carga de la prueba”, en: Revista de Derecho de la Pontificia Universidad Católica de Valparaíso XXXIII, Valparaíso, Chile, 20 semestre 2009. 